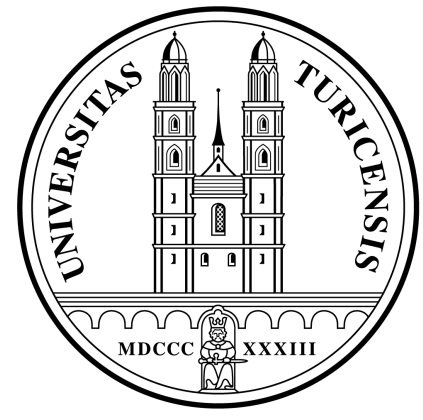

Institute for Empirical Research in Economics

University of Zurich

Working Paper Series

ISSN 1424-0459

Published in: 'European Economic Review', May 2000, Vol. 44

Working Paper No. 20

Fairness, Incentives, and Contractual Choices

Ernst Fehr and Klaus M. Schmidt

September 1999 


\title{
Fairness, Incentives, and Contractual Choices
}

\author{
Ernst Fehr ${ }^{\mathrm{a}}$ \\ University of Zurich \\ Klaus M. Schmidt ${ }^{\mathrm{b} *}$ \\ University of Munich and CEPR
}

September 1999

\begin{abstract}
This paper examines how the presence of a non-negligible fraction of reciprocally fair actors changes the provision of incentives through contracts. We provide experimental evidence that principals have a strong preference for less complete contracts although the standard self-interest model predicts that they should prefer the more complete contract. Our theoretical analysis shows that fairness concerns can explain this preference for less completeness. Fair principals keep their promises which provides strong pecuniary incentives through an incomplete contract. Selfish principals free-ride and exploit the agents. Counterintuitively, selfish agents are induced to work by an incomplete contract while fair agents shirk.
\end{abstract}

Keywords: Fairness, Reciprocity, Incomplete Contracts, Incentives

JEL Classification Numbers: C7, C9, D0, J3.

\footnotetext{
"Paper written for the invited session „Fairness in Strategic Interactions“ at the 14th Annual Congress of the European Economic Association in Santiago de Compostela, September 1-4, 1999. Alexander Klein and Susanne Kremhelmer provided excellent research assistance for the experiments discussed in this article. Financial support by Deutsche Forschungsgemeinschaft through grant SCHM-1196/4-1 is gratefully acknowledged. Ernst Fehr also gratefully acknowledges support from the Swiss National Science Foundation (project number 1214-05100.97) and the Network on the Evolution of Preferences and Social Norms of the MacArthur Foundation and the EU-TMR Research Network ENDEAR (FMRX-CTP98-0238).

${ }^{a}$ Ernst Fehr, Institute for Empirical Research in Economics, University of Zurich, Bluemlisalpstrasse 10, CH-8006 Zurich, Switzerland.

${ }^{\mathrm{b}}$ Klaus M. Schmidt, Department of Economics, University of Munich, Ludwigstr. 28, D-80539 Muenchen, Germany, email: klaus.schmidt@ Irz.uni-muenchen.de, Tel: +49-89-2180 2250, Fax: +49-89-2180-3510 (corresponding author).
} 


\section{Introduction}

We examine how the presence of fairness and equity motives changes and complicates the provision of incentives. Incentives are the essence of economics. A substantial amount of evidence has been accumulated during the last 15 years indicating that fairness considerations affect the behaviour of many people. For example, there is by now a lot of evidence suggesting that firms' wage setting is constrained by workers' views about what constitutes a fair wage and by workers' reciprocal responses to the wage offered. ${ }^{1}$ There is also evidence that fairness concerns are relevant for contractual design. ${ }^{2}$ A main feature of fair behaviour in many situations is, that in response to an act of $\mathrm{A}$ that is favourable to $\mathrm{B}, \mathrm{B}$ is willing to take costly actions to return at least part of the favour, and in response to an act that is perceived as harmful by B, B is willing to take costly actions to reduce A's material payoff. Note that B's reciprocal action occurs even if $\mathrm{B}$ derives no material benefit from it. Fairness, as we use the term in this paper, is thus not a form of altruism, i.e. of unconditional kindness, but a reciprocal response that occurs even in the absence of any material benefits.

In this paper we argue that reciprocally fair behaviour may render explicit contracts inferior relative to implicit contracts although - under the standard self-interest assumption the explicit contract is predicted to be better in terms of efficiency and in terms of the principal's expected material payoff. Our argument relies on strong experimental evidence and on a theoretical analysis that is based on the model of inequity aversion by Fehr and Schmidt (1999). ${ }^{3}$ The experiment under consideration is part of a sequence of experiments on incomplete contracts that are described and analysed in more detail in Fehr, Klein and Schmidt (1999) and Schmidt, Kremhelmer and Fehr (1999). In the experiment principals had the choice between an explicit contract and an implicit contract. In the explicit contract principals explicitly conditioned a fine on the agent's deviation from a desired effort level. In the implicit contract they could not do this. Instead they could promise to pay a bonus after they have observed the agent's effort. The promise was, however, not binding and merely cheap talk. The possibility to credibly condition the fine on the actual effort level renders the explicit contract more complete than the implicit contract.

\footnotetext{
${ }^{1}$ See, e.g. Bewley (1995) or Agell and Lundberg (1995).

${ }^{2}$ For example, Fehr, Gächter and Kirchsteiger (1997) have shown that reciprocal fairness causes a large increase in the set of enforceable contracts and, hence, large efficiency gains relative to the predictions of the standard approach that assumes that everybody is completely selfish.

${ }^{3}$ Recently several model of equity and reciprocity have been developed. For other generally applicable approaches see, e.g., Bolton and Ockenfels (forthcoming), Falk and Fischbacher (1998) or Dufwenberg and Kirchsteiger (1998). For a combination of stochastic game theory with our theory of inequity aversion see Goeree and Holt (1999).
} 
In contrast to the standard prediction the implicit contract was chosen in the vast majority ( 88 percent) of all cases and agents' effort levels were much higher under this contract. The data pattern together with our theoretical analysis suggests that the presence of fair types and the peculiarities of their interaction with the selfish types was crucial for this outcome. First of all, and most importantly, the presence of fair principals implies that the promised bonus does not merely represent cheap talk because fair principals can and do in fact condition the bonus payment on the effort level. Their capability to actually commit to paying a conditional bonus is based on their fairness preferences. Conditional bonus payments, in turn, provide a strong pecuniary incentive for the agents to perform as desired by the principals. Interestingly, however, our analysis suggests that the fair-minded agents do not provide the desired effort level but they shirk because they are afraid of being cheated by the selfish principals. Thus, the presence of fair principals induces selfish agents to perform while the presence of selfish principals induces the fair agents to shirk under the implicit contract. The overall result of this interaction between the types is that an appropriately chosen implicit contract elicits, on average, higher effort levels than the explicit contract and is, hence, more profitable for fair principals. This implies that the same implicit contract is even more profitable for the selfish principals because they never pay the bonus but receive, on average, the same effort from the agents. This is so because the selfish principals mimic the offers of the fair principals and, therefore, agents do not know the principal's type. As a consequence, both selfish and fair principals have a preference for the implicit contract.

\section{The experiment}

The structure of the game that was played in the experiments is as follows. There is a principal who can hire one agent whom he wants to spend effort, $e$, in her firm. The production function is linear in effort and given by $a \cdot e, a>0$. Effort is costly to the agent and the effort cost function $c(e)$ is strictly increasing and convex in $e$.

At stage 1, the principal has to decide what kind of contract to offer to the agent. She can choose between an ,implicit“ and an ,explicit“ contract. An implicit contract specifies a fixed wage, $w$, and a desired effort level $e^{*}$, with $w \geq c\left(e^{*}\right)$. In addition, the principal can announce a bonus, $b^{*}$, that may be paid after actual effort $e$ has been observed. There is no contractual obligation to pay the announced bonus, nor is the agent obliged to choose $e^{*}$. An explicit contract also specifies a fixed wage, $w$, and a desired effort level $e^{*}$, with $w \geq c\left(e^{*}\right)$. 
Here, however, the principal can impose a fine, $f$, on the agent that has to be paid to the principal with probability $1 / 3$ if the actual effort level of the agent falls short of $e^{*}$. The fine is bounded above by some exogenously given maximum level $f$ '. If the principal chooses the explicit contract, she has to incur a small fixed cost, $k$.

At stage 2, the agent observes what contract has been offered and decides whether to accept or reject the offer. If he rejects, the game ends and both parties get a payoff of 0 . If he accepts, he has to choose his actual effort level, $e$.

At stage 3 the principal observes the actual effort level. If she has offered an implicit contract, she now has to decide on the actual bonus payment, $b$, to the agent. If she has offered an explicit contract and if the agent's effort falls short of $e^{*}$, a random draw decides with probability $1 / 3$ whether the agent is fined. Finally, payoffs are made.

If all players have purely selfish preferences, the analysis of this game is straightforward. A selfish principal would never pay a bonus, so $b=0$. Anticipating this, there is no incentive for the agent to spend more than the minimum effort, $\underline{e}$. Hence, if the principal chooses the implicit contract, she should offer $w=c(\underline{e})$. This gives her a payoff $U^{P}=a \underline{e}-c(\underline{e})$ while the agent gets a payoff of 0 . If the principal chooses the explicit contract, she should

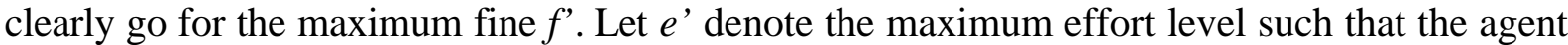
prefers to choose $e$ ' rather than to choose $e=\underline{e}$ and to pay the fine $f$ ' with probability $1 / 3$, and assume that $e^{\prime}$ is smaller that the efficient effort level, $e^{F B}$. Then the optimal explicit contract has $w=c\left(e^{\prime}\right), e^{*}=e^{\prime}$, and $f=f^{\prime}$ which gives a payoff $U^{P}=a e^{\prime}-c\left(e^{\prime}\right)-k$ to the principal and a payoff of 0 to the agent. If $e^{\prime}>\underline{e}$ and $k$ is not too large, the explicit contract is optimal.

We ran this experiment in two sessions with 46 subjects over 10 periods. A session lasted approximately 2.5 hours and, on average, a subject earned 65 German Marks (DM). The subjects were undergraduate students of law at the University of Munich. In each period (consisting of the three stages described above) each agent was matched to a different principal and this was known by all subjects. We chose parameters to be $a=10, e \in\{1, \ldots, 10\}$, $k=10$ and $f^{\prime}=13$. The agent's cost function is such that $c(1)=0, c(10)=20$ and $1 \leq c^{\prime}(e) \leq 4{ }^{4}$ Hence, the efficient effort level is $e^{F B}=10$. The maximum fine was chosen such that $e^{\prime}=4$. If all players have purely selfish preferences, then the subgame perfect equilibrium payoff to the

${ }^{4}$ The exact cost function was given by
\begin{tabular}{|l|l|l|l|l|l|l|l|l|l|l|}
\hline $\mathrm{e}$ & 1 & 2 & 3 & 4 & 5 & 6 & 7 & 8 & 9 & 10 \\
\hline $\mathrm{c}(\mathrm{e})$ & 0 & 1 & 2 & 4 & 6 & 8 & 10 & 13 & 16 & 20 \\
\hline
\end{tabular}


principal if she chooses the optimal implicit contract is $U^{P}=10$ while she would get $U^{P}=10 e^{\text {, }}$ $-c\left(e^{\prime}\right)-k=40-4-10=26$ if she chooses the optimal explicit contract. Hence, the selfinterest-model predicts that all principals should opt for the explicit contract because much higher effort levels are predicted for this contract.

The experimental evidence is completely at odds with this prediction. Out of the 230 observations the explicit contract was chosen only 28 times with the fraction of explicit contracts declining over time. The fraction of explicit contracts declined from 13 percent in period one to 4 percent in period ten. In view of the relative profitability of explicit contracts this is not surprising because those who chose the explicit contract made an average loss of 9 tokens $(1$ token $=0.2 \mathrm{DM} \approx 0.12 \$ \mathrm{US}$ ) while those who chose the implicit contract made an average profit of 26 tokens. The average income of the agents was roughly the same for both contracts (18 tokens). The time paths of average wages, bonuses, effort levels and fines are depicted in Figure 1.

\section{Insert Figure 1 here}

Implicit contracts stipulate, on average, wages around 15 and the desired effort level is 6.6 while the actual effort level is 5.2. On average, the announced bonus is 25 and the actual bonus payment is 10.5 tokens. In view of the small number of observations for explicit contracts the data for explicit contracts must be interpreted with some caution. The average fine rose from 10 to the maximum fine $f^{\prime}=13$ over time. If the principals required the agents to choose effort levels that are enforceable with $f^{\prime}=13$ (i.e. $e^{* \leq 4}$ ), five out of six agents complied. However, it seems that many principals tried to induce a higher effort level by paying a more generous base wage and by requiring an effort $e^{*>4}$. Most of these attempts failed (in 18 out of 22 cases) and caused significant losses for the principals. On average the desired effort level under the explicit contract is 5.6 while the actual average effort is only 2.1 .

Among other things, Figure 1 exhibits two important results that are likely to drive contractual choices and that unambiguously refute the standard prediction with selfish individuals: (i) The average effort under the implicit contract is much higher than under the explicit contract. (ii) The average bonus payment is always positive. Moreover, as Table 1 indicates, there is a strong positive correlation between the actual effort and the average bonus payment.

\section{Insert Table 1 here}


These facts suggest the following intuitive explanation of contractual choices. Since higher effort levels are associated with significantly higher bonus payments, agents had a monetary incentive to put forward a relatively high effort level in the implicit contract. This, in turn, increased the relative profitability of this contract considerably and induced principals to prefer this contract. Note, that the average effort under the implicit contract is considerably above the effort that is enforceable in the explicit contract with selfish agents. ${ }^{5}$

In the following we provide a theoretical underpinning for the above intuitive explanation in terms of our model of inequity aversion. In Fehr and Schmidt (1999) we have shown that this model can organise a large amount of seemingly contradictory and puzzling data. We would like to stress that the above experiment has not been designed to test our theory nor do we believe that the experiment can be used to discriminate between different theories of fairness or reciprocity. Nonetheless, in view of the model's explanatory power in many other games, it is interesting to know what this model predicts for the above contract experiment, whether it can organise the major behavioural patterns in this experiment and whether the explanation provides new and interesting insights into the mechanisms that determine principals' contractual choices and agents' behavioural responses in the presence of fairness concerns.

\section{A simple model of inequity aversion}

In this section we briefly describe the model of inequity aversion by Fehr and Schmidt (1999). A basic assumption of our model is that there is a non-negligible fraction of inequity averse players. An individual is inequity averse if it dislikes outcomes that are perceived as inequitable or unfair. This assumption is based on strong empirical evidence that indicates that not only absolute but also relative payoffs have a strong impact on some people's well being and behaviour (see e.g. Loewenstein et al. 1989, Clark and Oswald 1996). This definition raises, of course, the difficult question how individuals measure or perceive the fairness of outcomes. The determination of the relevant reference group and the relevant reference payoff may be affected by the social context, the saliency of particular individuals, the social proximity among individuals and several other factors and is ultimately an empirical question. If, however, we restrict attention to individual behaviour in economic

\footnotetext{
${ }^{5}$ One also might conjecture that the preference for implicit contracts is caused by the fact that the explicit contract involves a punishment while the implicit contract involves a reward. However, we could rule out this
} 
experiments, then it is natural to assume that the reference group is simply the set of subjects playing against each other and that the reference point, i.e. the equitable outcome, is given by the egalitarian outcome. ${ }^{6}$

More precisely, we assume that inequity averse players experience a utility loss if they are worse off in material terms than the other players in the experiment and they also dislike to be better off. In our context it suffices to consider the two-player case. ${ }^{7}$ Let $x=\left(x_{1}, x_{2}\right)$ denote the vector of monetary payoffs. The utility function of player $i \in\{1,2\}$ is given by

$$
U_{i}(x)=x_{i}-\alpha_{i} \max \left\{x_{j}-x_{i}, 0\right\}-\beta_{i} \max \left\{x_{i}-x_{j}, 0\right\}, \quad i \neq j .
$$

where we assume $\beta_{i} \leq \alpha_{i}$ and $0 \leq \beta_{i}<1$. The second term in (1) measures the utility loss from disadvantageous inequality, while the third term measures the loss from advantageous inequality.

To evaluate the implications of this utility function note that we assume that the utility function is linear in inequality as well as in $x_{i}$. This implies that the marginal rate of substitution between monetary income and inequality is constant. This may not be completely realistic, but surprisingly many experimental observations that seem to contradict each other can be explained on the basis of this very simple utility function already.

Furthermore, we assume $\alpha_{i} \geq \beta_{i}$, i.e., a player suffers more from inequality that is to his disadvantage. We also assume that $\beta_{i}<1$. To interpret this restriction suppose that player $i$ has a higher monetary payoff than player $j$. In this case $\beta_{i}=0.5$ implies that player $i$ is just indifferent between keeping 1 Dollar to himself and giving this Dollar to player $j$. If $\beta_{i}=1$, then player $i$ is prepared to throw away 1 Dollar in order to reduce his advantage relative to player $j$ which seems very implausible. This is why we do not consider the case $\beta_{i} \geq 1$. On the other hand, there is no justification to put an upper bound on $\alpha_{i i}$. To see this suppose that player $\mathrm{i}$ has a lower monetary payoff than player $\mathrm{j}$. In this case player $i$ is prepared to give up one Dollar of his own monetary payoff if this reduces the payoff of his opponent by $\left(1+\alpha_{i}\right) / \alpha_{i}$ Dollars. For example, if $\alpha_{i}=2$, then player i is willing to give up one Dollar if this reduces the payoff of his opponent by 1.5 Dollars.

\footnotetext{
explanation through a control experiment.

${ }^{6}$ See Fehr and Schmidt (1999) for a more extensive discussion of the points raised in this paragraph.

${ }^{7}$ See Fehr and Schmidt (1999) for the formal description of the $n$-player case.
} 


\section{Fairness and incomplete contracts}

In the following we analyse our experimental game by using the theory of inequity aversion. To simplify the calculations we assume that there are only two types of players. $40 \%$ of the population is inequity averse with parameters $\alpha_{i}, \beta_{i}>0.5 .60 \%$ of the population is completely selfish with $\alpha_{i}=\beta_{i}=0$. This distribution is roughly consistent with the evidence on other games. ${ }^{8}$ Our analysis proceeds in two steps. First we show that there exists a perfect Bayesian equilibrium in which selfish principals mimic the contract offers of the inequity averse principals by proposing the same implicit contract. As we will see, the details of this contract are quite similar to what we observe in the experiment. Next we show, that, in equilibrium, the inequity averse principals cannot signal their type by proposing implicit contracts that differ from the contracts of the selfish types. Although we cannot, of course, prove, that subjects actually played the equilibrium described below, we believe that our propositions provide, first, a reasonable description of the evidence and, second, interesting and potentially important insights about how contractual choices are shaped by the interaction between selfish and inequity averse types.

Proposition 1: There exists a perfect Bayesian pooling equilibrium in this game with the following equilibrium path properties. Both, the selfish and the inequity averse principal will choose a payoff-equalising implicit contract $\left(w, e^{*}, b^{*}\right)$ with $w=10, e^{*}=7$ and $b^{*}=30$. The inequity averse agents do not cooperate and choose $e=1$. The selfish agents, however, do cooperate and choose $e=7$. At stage 3, no bonus is being paid if $e=1$. If $e=7$, then the inequity averse principal pays the announced bonus, while the selfish principal chooses $b=0$.

Before we prove Proposition 1 in more detail we would like to emphasise that the equilibrium characterised above is not the only pooling equilibrium. It will be easy to see from the proof below that perfect Bayesian pooling equilibria with $w \geq 10$ can be sustained, in which the bonus payment made by the inequity averse principal is reduced so that $b+w=40$. Furthermore, since $e^{*}$ and $b^{*}$ have no direct payoff consequences there are many other pooling equilibria with the same physical outcome but different announcements of $e^{*}$ and $b^{*}$. In all these pooling equilibria the selfish agent chooses $e=7$ and the inequity averse agent chooses $e=1$. In our view, it is worthwhile to stress that these pooling equilibria describe subjects' behaviour in the experimental game surprisingly well. Remember that 88 percent of

\footnotetext{
${ }^{8}$ See Fehr and Schmidt (1999) for more details. The qualitative results of the analysis remain unchanged for a more spread out distribution of types, as long as there is a significant fraction of selfish players.
} 
all offers were implicit contracts and this fraction increased to 96 percent in the $10^{\text {th }}$ period. Moreover, the average wage was 15 and average promised bonus payments were 25 which gave, in sum, exactly 40. The desired average effort was 6.6 and actual average effort was 5.2. According to Proposition 1 we should observe a desired effort of $e^{*}=7$ and an actual average effort of $0.4 \cdot 1+0.6 \cdot 7=4.6$ since there are 40 percent inequity averse agents and 60 percent selfish agents. In the experiment we observed average bonus payments of 10.5 and according to the Proposition 1 we should observe payments of $0.4 \cdot 30+0.6 \cdot 0=12$ on average. Note, however, that pooling equilibria with lower bonus payments exist as well.

The equilibrium in Proposition 1 can be sustained by the following off-equilibriumpath strategies and beliefs. If the principal does not choose the implicit contract given in the proposition, then the agent believes that he faces the selfish principal with probability one. Hence, off the equilibrium path the agent does not expect to get a bonus, so he always chooses $e=1$ if he is offered an implicit contract. If he is offered an explicit contract $\left(w, e^{*}, f\right)$, then the selfish agent chooses $e=1$ if $w-1 / 3 f>w-c\left(e^{*}\right)$. Otherwise he chooses $e=e^{*}$. If $w \geq 17$, the inequity averse agent chooses $e \geq 4$ so as to equalise payoffs, i.e. $w-c(e)=10 e-w-k{ }^{9}$ If $w<17$, the inequity averse agent either rejects the contract or accepts it and chooses $e=e^{*}$, depending on whether $0>w-c\left(e^{*}\right)-\alpha\left[10 e^{*}-2 w-k+c\left(e^{*}\right)\right]$.

To see that this is indeed an equilibrium consider first the principal's bonus decision at date 3. A selfish principal $(\beta=0)$ will always choose $b=0$. An inequity averse principal $(\beta$ > 0.5) prefers to pay a bonus that equalises the monetary payoff of the principal and the monetary payoff of the agent: $10 e-w-b=w+b-c(e)$, which implies $b(e)=[10 e+c(e)] / 2-w$ and $U^{P}=U^{A}=[10 e-c(e)] / 2$. Note that this behaviour of the inequity averse principals means that actual bonus payments are increasing in effort. In a pooling equilibrium the agent believes at stage 2 that he faces an inequity averse principal with probability $p=0.4$. Thus, his expected payoff as a function of $e$ is given by

$$
U^{A}(e)=p[10 e-c(e)] / 2+(1-p)[w-c(e)-\alpha(10 e-w-w+c(e))]
$$

Substituting the parameters of the experiment and differentiating with respect to $e$ yields

$$
d U^{A} / d e=2-6 \alpha-(0.8+0.6 \alpha) c^{\prime}(e)
$$

If $\alpha=0$, then $d U^{A} / d e \geq 0$ if and only if $c^{\prime}(e) \leq 2.5$. Hence, given the convex cost function a selfish agent would choose an effort of $e=7$. If $\alpha>0.5$, then $d U^{A} / d e$ is always negative, so an inequity averse agent would choose the minimum effort level $e=1$. It is interesting to note that

\footnotetext{
${ }^{9}$ There is an integer problem with the choice of $e$ that slightly complicates the analysis. However, it does not affect the result.
} 
it is the selfish player who engages in effort hoping to get a bonus, while the inequity averse player does not do so because he suffers too much if the bonus is not being paid. ${ }^{10}$

If the selfish principal sticks to the equilibrium strategy and offers $\left(w=10, e^{*}=7\right.$, $b^{*}=30$ ) at stage 1 , then her expected payoff is given by

$$
U^{P s}=0.6[70-10]+0.4[10-10]=36
$$

Clearly, offering another implicit contract cannot be optimal because agents then believe that they face a selfish principal for sure. If the principal offers an explicit contract, then one can show that her optimal explicit offer would be $\left(w=4, e^{*}=4, f^{\prime}=13\right)$ which is accepted by the selfish agent and rejected by the inequity averse agent and yields an expected payoff of $0.6[40-4-10]=15.6$. Hence, this deviation does not pay either.

Finally, consider the inequity averse principal. If she sticks to the equilibrium strategy, her expected utility is given by

$$
U^{P i}=0.6[70-10-30]+0.4[10-10-\alpha(10-0)]=18-4 \alpha
$$

Again, deviating to another implicit contract cannot be optimal. If she chooses an explicit contract, it can be shown that she should offer $\left(w=17, e^{*}=4, f^{\prime}=13\right)$. This offer will be accepted by both agents, all agents choose $e=4$, and the payoff to the principal and to the agent are equalised. This yields a payoff to the principal of $40-17-10=13$. Hence, a deviation does not pay if $\alpha<1.25$.

In the pooling equilibrium of Proposition 1 the inequity averse principal suffers from the existence of selfish principals because their presence induces inequity averse agents to shirk. It would, thus, be in the interest of the inequity averse principal to signal her type so that all agents believe that she will pay the promised bonus. However, as Proposition 2 shows this is not possible in equilibrium.

Proposition 2: There is no perfect Bayesian equilibrium in which the inequity averse principal offers an implicit contract that differs from the contract offered by the selfish type.

To see this, suppose that there is a separating equilibrium in which the inequity averse principal offers an implicit contract $\left(w_{i}, e_{i}{ }^{*}, b_{i}{ }^{*}\right)$ and in which the agent believes that he faces the inequity averse principal with probability one after observing this offer. Note first that if $w_{i}<40$, then both, the selfish and the inequity averse agent will choose $e=10$ because they know that they are going to get the bonus $b(e)=[a e-c(e)] / 2-w$ for sure. If $w_{i} \geq 40$, then an

\footnotetext{
${ }^{10}$ Note also that if agents were not inequality averse but altruistic, then all agents would choose a high effort level.
} 
inequity averse principal will not pay an additional bonus even if $e=10$. Therefore with $w_{i} \geq$ 40 the selfish agent would choose $e=1$ which implies that the inequity averse principal gets a negative expected payoff. This cannot happen in equilibrium, so we must have $w_{i}<40$. Consider now the selfish principal. If she is supposed to offer an implicit contract $\left(w_{s}, e_{s}^{*}, b_{s}{ }^{*}\right)$, then both agents will choose $e=1$ because they know that they face the selfish principal. Therefore, her payoff must be smaller than 10. If she is supposed to offer an explicit contract, then we know from the proof of Proposition 1 that the optimal contract gives her a payoff of 15.6. However, if she mimics the inequity averse principal and also offers $\left(w_{i}, e_{i}^{*}, b_{i}{ }^{*}\right)$, then both types of the agent would choose $e=10$ and the selfish principal gets $U^{P s}=100-w>60$. Hence, the selfish principal would always want to mimic the inequity averse principal and a separating equilibrium cannot exist.

\section{Concluding remarks}

Examining contractual choices and behavioural responses to different incentives schemes under the pure self-interest assumption is an important first step. Economic theory has made enormous progress in this regard during the last two decades. However, in view of the accumulating evidence that a non-negligible fraction of the population exhibits reciprocally fair behaviour, it is time to take this into account. Our results indicate that the presence of fair actors has non-obvious, interesting and important consequences. There is definitely no scarcity of topics for future theoretical and empirical research in this area. 


\section{References}

Agell, J., Lundberg, P., 1995. Theories of pay and unemployment: Survey evidence from Swedish manufacturing firms. Scandinavian Journal of Economics 97, 295-308.

Bewley, T., 1995. A depressed labor market as explained by participants. American Economic Review, Papers and Proceedings 85, 250-254.

Bolton, G.E., Ockenfels, A., 1999. A theory of equity, reciprocity and competition. American Economic Review, forthcoming.

Clark, A.E., Oswald, A.J., 1996. Satisfaction and comparison income. Journal of Public Economics 61, 359-381.

Dufwenberg, M., Kirchsteiger, G., 1998. A theory of sequential reciprocity. Discussion Paper. CentER, Tilburg University.

Falk, A., Fischbacher, U., 1998. A theory of reciprocity. Discussion Paper. University of Zürich.

Fehr, E., Gächter, G. Kirchsteiger, G., 1997. Reciprocity as a contract enforcement device. Econometrica 65, 833-860.

Fehr, E., Schmidt, K.M., 1999. A theory of fairness, competition and cooperation. Quarterly Journal of Economics 114, 817-868.

Fehr, E., Klein, A., Schmidt, K.M., 1999. Individual vs. joint ownership: An experimental analysis of the endogenous allocation of ownership rights. Discussion Paper. University of Munich.

Goeree, J., Holt, C., 1999. Asymmetric inequality aversion and noisy behavior in alternatingoffer bargaining games. European Economic Review, forthcoming.

Loewenstein, G.F., Thompson, L., Bazerman, M.H., 1989. Social utility and decision making in interpersonal contexts. Journal of Personality and Social Psychology 57, 426-441.

Schmidt, K.M., Kremhelmer, S., Fehr, E., 1999. Why are contracts incomplete - an experimental examination. Discussion Paper. University of Munich. 
Explicit Contracts

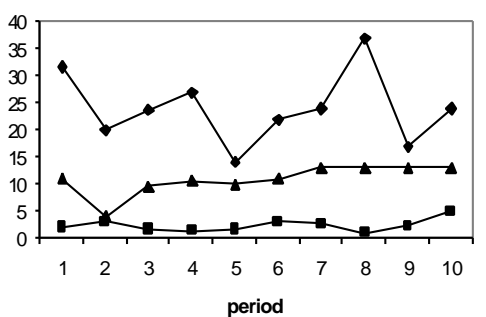

$\rightarrow$ av.wages $\rightarrow-$ av. effort $\rightarrow$ av. fines
Implicit Contracts

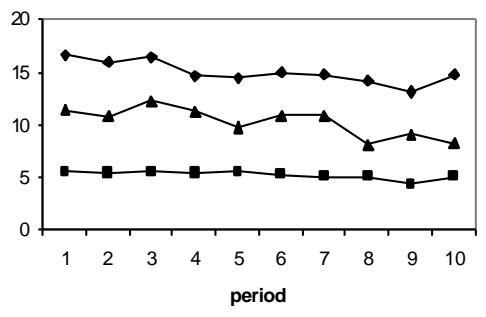

$\rightarrow$ av. wages $\rightarrow$ av. effort $\rightarrow$ av. bonus

Figure 1: Time path of contracts 


\begin{tabular}{|l|c|c|c|c|c|c|c|c|c|c|}
\hline Effort a & 1 & 2 & 3 & 4 & 5 & 6 & 7 & 8 & 9 & 10 \\
\hline Average bonusb & 0 & 0.17 & 223 & 5.31 & 10.08 & 8.95 & 13.75 & 19.04 & 23.46 & 28.77 \\
\hline
\end{tabular}

Table 1: Average bonus payment conditional on the actual effort level 


\section{Working Papers of the Institute for Empirical Research in Economics}

No.

1. Rudolf Winter-Ebmer and Josef Zweimüller: Firm Size Wage Differentials in Switzerland: Evidence from Job Changers, February 1999

2. Bruno S. Frey and Marcel Kucher: History as Reflected in Capital Markets: The Case of World War II, February 1999

3. Josef Falkinger, Ernst Fehr, Simon Gächter and Rudolf Winter-Ebmer: A Simple Mechanism for the Efficient Provision of Public Goods - Experimental Evidence, February 1999

4. Ernst Fehr and Klaus M. Schmidt: A Theory of Fairness, Competition and Cooperation, April 1999

5. Markus Knell: Social Comparisons, Inequality, and Growth, April 1999

6. Armin Falk and Urs Fischbacher: A Theory of Reciprocity, April 1999

7. Bruno S. Frey and Lorenz Goette: Does Pay Motivate Volunteers?, May 1999

8. Rudolf Winter-Ebmer and Josef Zweimüller: Intra-firm Wage Dispersion and Firm Performance, May 1999

9. Josef Zweimüller: Schumpeterian Entrepreneurs Meet Engel's Law: The Impact of Inequality on InnovationDriven Growth, May 1999

10. Ernst Fehr and Simon Gächter: Cooperation and Punishment in Public Goods Experiments, June 1999

11. Rudolf Winter-Ebmer and Josef Zweimüller: Do Immigrants Displace Young Native Workers: The Austrian Experience, June 1999

12. Ernst Fehr and Jean-Robert Tyran: Does Money Illusion Matter?, June 1999

13. Stefan Felder and Reto Schleiniger: Environmental Tax Reform: Efficiency and Political Feasibility, July 1999

14. Bruno S. Frey: Art Fakes - What Fakes?, An Economic View, July 1999

15. Bruno S. Frey and Alois Stutzer: Happiness, Economy and Institutions, July 1999

16. Urs Fischbacher, Simon Gächter and Ernst Fehr: Are People Conditionally Cooperative? Evidence from a Public Goods Experiment, July 2000

17. Armin Falk, Ernst Fehr and Urs Fischbacher: On the Nature of Fair Behavior, August 1999

18. Vital Anderhub, Simon Gächter and Manfred Königstein: Efficient Contracting and Fair Play in a Simple Principal-Agent Experiment, August 1999

19. Simon Gächter and Armin Falk: Reputation or Reciprocity?, September 1999

20. Ernst Fehr and Klaus M. Schmidt: Fairness, Incentives, and Contractual Choices, September 1999

21. Urs Fischbacher: $z$-Tree - Experimenter's Manual, September 1999

22. Bruno S. Frey and Alois Stutzer: Maximising Happiness?, October 1999

23. Alois Stutzer: Demokratieindizes für die Kantone der Schweiz, October 1999

24. Bruno S. Frey: Was bewirkt die Volkswirtschaftslehre?, October 1999

25. Bruno S. Frey, Marcel Kucher and Alois Stutzer: Outcome, Process \& Power in Direct Democracy, November 1999

26. Bruno S. Frey and Reto Jegen: Motivation Crowding Theory: A Survey of Empirical Evidence, November 1999

27. Margit Osterloh and Bruno S. Frey: Motivation, Knowledge Transfer, and Organizational Forms, November 1999

28. Bruno S. Frey and Marcel Kucher: Managerial Power and Compensation, December 1999

29. Reto Schleiniger: Ecological Tax Reform with Exemptions for the Export Sector in a two Sector two Factor Model, December 1999

30. Jens-Ulrich Peter and Klaus Reiner Schenk-Hoppé: Business Cycle Phenomena in Overlapping Generations Economies with Stochastic Production, December 1999

31. Josef Zweimüller: Inequality, Redistribution, and Economic Growth, January 2000

32. Marc Oliver Bettzüge and Thorsten Hens: Financial Innovation, Communication and the Theory of the Firm, January 2000

33. Klaus Reiner Schenk-Hoppé: Is there a Golden Rule for the Stochastic Solow Growth Model? January 2000

34. Ernst Fehr and Simon Gächter: Do Incentive Contracts Crowd out Voluntary Cooperation? February 2000

35. Marc Oliver Bettzüge and Thorsten Hens: An Evolutionary Approach to Financial Innovation, July 2000

36. Bruno S. Frey: Does Economics Have an Effect? Towards an Economics of Economics, February 2000

37. Josef Zweimüller and Rudolf Winter-Ebmer: Firm-Specific Training: Consequences for Job-Mobility, March 2000

The Working Papers of the Institute for Empirical Research in Economics can be downloaded in PDF-format from http://www.unizh.ch/iew/wp/ 


\section{Working Papers of the Institute for Empirical Research in Economics}

No.

38. Martin Brown, Armin Falk and Ernst Fehr: Contract Inforcement and the Evolution of Longrun Relations, March 2000

39. Thorsten Hens, Jörg Laitenberger and Andreas Löffler: On Uniqueness of Equilibria in the CAPM, July 2000

40. Ernst Fehr and Simon Gächter: Fairness and Retaliation: The Economics of Reciprocity, March 2000

41. Rafael Lalive, Jan C. van Ours and Josef Zweimüller: The Impact of Active Labor Market Programs and Benefit Entitlement Rules on the Duration of Unemployment, March 2000

42. Reto Schleiniger: Consumption Taxes and International Competitiveness in a Keynesian World, April 2000

43. Ernst Fehr and Peter K. Zych: Intertemporal Choice under Habit Formation, May 2000

44. Ernst Fehr and Lorenz Goette: Robustness and Real Consequences of Nominal Wage Rigidity, May 2000

45. Ernst Fehr and Jean-Robert Tyran: Does Money Illusion Matter? REVISED VERSION, May 2000

46. Klaus Reiner Schenk-Hoppé: Sample-Path Stability of Non-Stationary Dynamic Economic Systems, Juni 2000

47. Bruno S. Frey: A Utopia? Government without Territorial Monopoly, June 2000

48. Bruno S. Frey: The Rise and Fall of Festivals, June 2000

49. Bruno S. Frey and Reto Jegen: Motivation Crowding Theory: A Survey of Empirical Evidence, REVISED VERSION, June 2000

50. Albrecht Ritschl and Ulrich Woitek: Did Monetary Forces Cause the Great Depression? A Bayesian VAR Analysis for the U.S. Economy, July 2000

51. Alois Stutzer and Rafael Lalive: The Role of Social Work Norms in Job Searching and Subjective Well-Being, July 2000

52. Iris Bohnet, Bruno S. Frey and Steffen Huck: More Order with Less Law: On Contract Enforcement, Trust, and Crowding, July 2000

53. Armin Falk and Markus Knell: Choosing the Joneses On the Endogeneity of Reference Groups, July 2000

54. Klaus Reiner Schenk-Hoppé: Economic Growth and Business Cycles: A Critical Comment on Detrending Time Series, August 2000

The Working Papers of the Institute for Empirical Research in Economics can be downloaded in PDF-format from http://www.unizh.ch/iew/wp/

Institute for Empirical Research in Economics, Blümlisalpstr. 10, 8006 Zürich, Switzerland

Phone: 004116343705 Fax: 004116344907 E-mail: bibiewzh@iew.unizh.ch 